10. Buttner H., AN, 207, 1918, P. 179-182

11. http://www.ipa.nw.ru/halley/en/download.html.

12. http://ssd.jpl.nasa.gov/sbdb_query.cgi\#x.

13. Dybczyński, Piotr A.; Królikowska, MałgorzataTowards a better understanding of the apparent source/sources of long period comets// Planetary and Space Science, 2016 V.123, p. 77-86.

14. Yeomans, D. K.; Chodas, P. W.; Sitarski, G.; Szutowicz, S.; Królikowska, M. Cometary orbit determination and nongravitational forces//Comets II, M. C. Festou, H. U. Keller, and H. A. Weaver (eds.), University of Arizona Press, Tucson, 2004., p. 137-151.

15. Aksnes, K.; Mysen, E. Nongravitational Forces on Comets: An Extension of the Standard Model//The Astronomical Journal, 2011, V. 142, Issue 3, article id. $81,4 \mathrm{pp}$.

N. Kovalenko, Ph.D.

Надійшла до редколегії 11.07.16

Astronomical Observatory of NAtional Taras Shevchenko University of Kyiv

\title{
ESTIMATION OF THE NON-GRAVITATIONAL EFFECTS ON THE CENTAURS ORBITS EVOLUTION
}

In this work the orbital evolution of some active Centaurs is considered for one thousand years with and without nongravitational accelerations. An impact assessment of nongravitational effects on Centaurs' orbits is made. It is shown that a shift in the date of perihelion passage for Centaurs population objects under consideration ranges from 1 second to 79 seconds for one orbit period and from $1 \mathrm{sec}$ to 0.72 days for the entire period of integration (a thousand years).

Н. Коваленко, канд. физ.-мат. наук

Астрономическая обсерватория Киевского национального университета имени Тараса Шевченко

\section{ОЦЕНКА ВЛИЯНИЯ НЕГРАВИТАЦИОННЫХ ЭФФЕКТОВ НА ЭВОЛЮЦИЮ ОРБИТ КЕНТАВРОВ}

В роботе рассмотрена орбитальная эволюция некоторых активных Кентавров на одну тысячу лет с учётом и без учета негравитационных ускорений. Получена оценка влияния негравитационных эффектов на эволюцию орбит Кентавров. Показано, что смещение по дате прохождения перигелия для рассмотренных объектов популяции Кентавров достигает от 1 до 79 сек за один оборот и от 1 до 0,72 сут. за весь период интегрирования (около тысячи лет).

В. І. Жданов, д-р фріз.-мат. наук, проф. Астрономічна Обсеваторія Київського національного університету імені Тараса Шевченка КНУ імені Тараса Шевченка

О. С. Сташко, студ. фріз. фр-ту, Київський національний університет імені Тараса Шевченка

\section{РУХ ПРОБНИХ ТІЛ У СТАТИЧНОМУ ГРАВІТАЦІЙНОМУ ПОЛІ СФЕРИЧНО-СИМЕТРИЧНОЇ СКАЛЯРНО-ПОЛЬОВОЇ КОНФІГУРАЦІЇ В ЗАГАЛЬНІЙ ТЕОРІЇ ВІДНОСНОСТІ}

Досліджено часткові точні розв'язки спільної системи рівнянь Ейнштейна та рівнянь скалярного поля з мінімальним 36'язком та ненульовим потенціалом самодії, які описують сферично-симетричні статичні конфігурації у випадку асимптотично-плоского простору-часу за наявності голої сингулярності у центрі. Для цих розв'язків проаналізовано рух пробних тіл, що взаємодіють тільки гравітаційно. Знайдено умови, за яких існують незв'язні області стійких колових орбіт. Показано існування траєкторій з нульовим кутовим моментом, коли частинки "зависають" на певній відстані від центру.

1. Вступ та базові співвідношення. Скалярні поля використовують в моделях динамічної темної енергії, де їхня присутність забезпечує вирішення відомих проблем горизонту та площинності (див., напр., [1-3]). Зазвичай вважають, що ці поля відігравали важливу роль на дуже ранніх стадіях еволюції Всесвіту, але в сучасну епоху їх вплив на будову релятивістських астрофрізичних об'єктів $€$ нехтовно малим. Разом із тим добре відомо, що наявність малого скалярного поля в загальній теорії відносності (ЗТВ) може кардинально міняти топологічну структуру простору-часу гравітуючої конфрігурації [3-5] - зокрема, призводити до появи голої сингулярності (ГС). Втім, це не завжди може бути помітним з точки зору віддаленого спостерігача. Індикатором наявності (або відсутності) ефректів скалярного поля може бути структура розподілу колових орбіт. Зокрема, у випадку розв'язку [4, 5] з безмасовим скалярним полем виникають області стійких колових орбіт, що не перетинаються [6].

Ми розглядаємо це питання на прикладі часткових розв'язків спільної системи рівнянь Ейнштейна та рівнянь скалярного поля 3 ненульовим потенціалом самодії, що описують сфрерично-симетричну статичну конфрігурацію 3 асимптотично-плоским простором-часом та голою сингулярністю у центрі. Обговорення голих сингулярностей у 3 ТВ має тривалу історію. За гіпотезою Пенроуза ГС не виникають в реальних астрофізичних системах, але ця гіпотеза наразі не $є$ ні строго доведеною, ані спростованою (див., напр., обговорення у книзі [3]).

Функціонал дії за наявності самогравітуючого скалярного поля $\phi €$

$$
S=S_{G R}+\int d^{4} x \sqrt{|g|}\left[\frac{1}{2} g^{\mu v} \phi_{, \mu} \phi_{, v}-V(\phi)\right],
$$

де $S_{G R}$ - стандартна гравітаційна дія загальної теорії відносності (див., напр., [2, 3]), V(ф) -потенціал самодії скалярного поля, який буде уточнено нижче. Метрика статичного сферично-симетричного простору-часу в "квазіглобальних" координатах [7,8] має вигляд

$$
d s^{2}=A(x) d t^{2}-\frac{1}{A(x)} d x^{2}-r^{2}(x)\left(d \theta^{2}+\sin ^{2}(\theta) d \varphi^{2}\right)
$$


Нетривіальні рівняння Ейнштейна, що випливають з (1) для метрики (2), мають такий вигляд:

$$
\frac{d}{d x}\left(\frac{d A}{d x} r^{2}\right)=-2 r^{2} V(\phi), \frac{d^{2} r}{d x^{2}}+\frac{1}{2} r\left(\frac{d \phi}{d x}\right)^{2}=0, \quad A \frac{d^{2} r^{2}}{d x^{2}}-r^{2} \frac{d^{2} A}{d x^{2}}=2 .
$$

До цих рівнянь можна додати рівняння для скалярного поля, але воно не є незалежним. 3 рівнянь (3) випливають еквівалентні ним співвідношення

де C - стала інтегрування,

$$
A(x)=r^{2}(x) \int_{x}^{\infty} \frac{2 x^{\prime}-C}{r^{4}\left(x^{\prime}\right)} d x^{\prime}
$$

$$
\phi(x)= \pm \int_{x}^{\infty} \sqrt{-\frac{2}{r} \frac{d^{2} r}{d x^{2}}}, V(x)=\frac{1}{r^{2}}-\frac{A}{r^{2}}\left(3\left(\frac{d r}{d x}\right)^{2}+r \frac{d^{2} r}{d x^{2}}\right)-\frac{C-2 x}{r^{3}} \frac{d r}{d x} .
$$

Звідси випливає один з методів побудови часткових розв'язків системи (3) (див., напр., [7]), який інколи називають "методом оберненої задачі". Замість того, щоб для заданого потенціалу $V(\phi)$ шукати функції $A(x), r(x), \phi(x)$, можна задати одну з цих функцій, наприклад, $r(x)$, і підбирати $A(x), \phi(x)$ та $V(\phi)$. У цьому разі задача вирішується у квадратурах згідно $(4,5)$, причому дві залежності (5) визначають $V(\phi)$ у параметричному вигляді за умови $r^{-1} d^{2} r / d x^{2}<0$. Цей підхід було використано для розв'язання різних задач у багатьох роботах [7-10].

2. Розв'язки рівнянь поля. Покладемо

$$
r(x)=x\left[1-\left(\frac{x_{0}}{x}\right)^{N}\right], \quad N>1 .
$$

Очевидно, за $x>x_{0}$ маємо $r>0, d^{2} r / d x^{2}<0$, тобто виконано умови застосовності методу оберненої задачі. Нас цікавлять розв'язки, що описують конфігурацію з масою $m>0$, тобто з асимптотикою на великих відстанях від центру $A(x)=1-2 m / x+O\left(x^{-N}\right)$. За допомогою розкладу формули (4) по $x^{-1}$ отримуємо $C=6 m$. Обчислення інтегралів в $(4,5)$ дає за $x>x_{0}$

$$
\begin{array}{r}
A(x)=\left[1-\left(\frac{x_{0}}{x}\right)^{N}\right]^{2}\left\{F\left[4, \frac{2}{N}, 1+\frac{2}{N},\left(\frac{x_{0}}{x}\right)^{N}\right]-\frac{C}{3 x} F\left[4, \frac{3}{N}, 1+\frac{3}{N},\left(\frac{x_{0}}{x}\right)^{N}\right]\right\}, \\
\phi(x)= \pm \sqrt{\frac{8(N-1)}{N}} \arcsin \left[\left(\frac{x_{0}}{x}\right)^{N / 2}\right]
\end{array}
$$

Потенціал $V(x)$ отримуємо прямою підстановкою функцій $A(x), r(x)$ в (5), а потім $V(\phi)$ за допомогою формули

$$
x=x_{0}\left\{\sin \left(|\phi| \sqrt{\frac{N}{8(N-1)}}\right)\right\}^{-2 / N} .
$$

Далі зосередимося на конфігураціях з голою сингулярністю у центрі $x=x_{0}$, яка, згідно з [12], має місце за умови $2 x_{0}>C .3$ урахуванням (4) та явного вигляду функції $r(x)(6)$ маємо таку асимптотику в околі $x_{0}$ :

$$
A(x)=\frac{2\left(x_{0}-3 m\right)}{3 N} \frac{1}{r(x)}, \quad x \rightarrow x_{0},
$$

таким чином, ця функція спочатку спадає, а при $x \rightarrow \infty$ зростає. Тому вона обов'язково має точку мінімуму. Можна показати, що $V(\phi) \rightarrow-\infty, \quad \phi \rightarrow \pi \sqrt{2(1-1 / N)}$, тобто потенціал скалярного поля $є$ необмеженим знизу. Зауважимо, що потенціали, які не є додатно визначеними, вже давно не є екзотикою у космології $[7,11]$.

3. Траєкторії руху пробних тіл. У випадку метрики (2) стандартний розгляд інтегралів руху пробних тіл для геодезичних у сорерично-симетричному просторі-часі

$$
A(x)\left(\frac{d t}{d \tau}\right)=p_{t}, \quad r^{2}(x)\left(\frac{d \varphi}{d \tau}\right)=L, \quad \theta=\pi / 2
$$

( $\tau$ - канонічний параметр на часоподібних геодезичних) та інтегралу нормування приводить до рівняння першого порядку

$$
\left(\frac{d x}{d \tau}\right)^{2}=p_{t}^{2}-V_{\text {eff }}(x)
$$

яке формально має вид рівняння руху нерелятивістської частинки у полі з ефективним потенціалом $V_{\text {eff }}=\alpha V_{1}+V_{2}$, де $\alpha=L^{2}$,

$$
V_{1}(x)=\frac{A(x)}{r^{2}(x)}=2 \int_{x}^{\infty} \frac{x^{\prime}-3 m}{r^{4}\left(x^{\prime}\right)} d x^{\prime}, \quad V_{2}(x)=A(x)
$$

Мінімуми потенціалу $V_{\text {eff }}$ при деяких фріксованих $\alpha$ відповідають стійким коловим орбітам з відповідним значенням кутового моменту $L$, а максимуми - нестійким коловим орбітам, що є граничними циклами для траєкторій пробних тіл. У точці мінімуму 


$$
\alpha V_{1}^{\prime}+V_{2}^{\prime}=0
$$

Очевидно $d V_{1} / d x<0$, тоді як знак $d V_{2} / d x$ змінюється з від'ємного на додатний. За великих $x, A(x) \approx 1-2 m / x$, $V_{1}(x) \sim 1 / x^{2}$, тому внесок $V_{2}$ в $V_{\text {eff }}$ переважає за будь-яких $\alpha$ i $d V_{\text {eff }} / d x>0$. Навпаки, за $x \rightarrow x_{0}$ маємо $d V_{\text {eff }} / d x<0$, тому хоча б один мінімум $V_{\text {eff }}$ завжди існує.

Проаналізуємо, коли можлива поява додаткових мінімумів. Біфуркаційним параметром $є \alpha$. У точці біфуркації

$$
\alpha V_{1}^{\prime \prime}+V_{2}^{\prime \prime}=0 \text {. }
$$

3 (12), (13) видно, що біфуркаційні значення $\alpha=L^{2}$ (якщо вони є) мають визначатися 3 формули $\alpha=-V_{2}^{\prime}\left(x_{b}\right) / V_{1}^{\prime}\left(x_{b}\right)$, де $x_{b} \in$ нулем функції $H(x)=V_{2}^{\prime \prime}(x)-V_{1}^{\prime \prime}(x) V_{2}^{\prime}(x) / V_{1}^{\prime}(x)$ або, з урахуванням (4),

$$
H(x)=2\left[\frac{r^{\prime \prime}(x)}{r(x)}+\frac{r^{\prime 2}(x)}{r^{2}(x)}\right] A(x)-\frac{2}{r^{2}(x)}+\left[\frac{r(x) r^{\prime}(x)}{x-3 m} A(x)-1\right] \cdot\left[\frac{8 r^{\prime}(x)}{r^{3}(x)}(x-3 m)-\frac{2}{r^{2}(x)}\right]
$$

Залежно від кількості нулів цієї фрункції можна зробити висновок про існування додаткових мінімумів $V_{\text {eff }}$.

При $x \rightarrow x_{0}$ маємо асимптотику, з урахуванням (9) та (6), $H(x) \approx-\frac{4 N}{3} \frac{x_{0}-3 m}{r^{3}(x)}$.

При $x \rightarrow \infty$ маємо $H(x) \approx \frac{2 m}{x^{3}}$. Принаймні, один нуль $H(x)$ завжди існує, оскільки ця функція змінює знак. Наприклад, при $x_{0}=1, C=1$ додаткові два нулі з'являються, коли $N$ стає більшим приблизно 4.6; це $€$ необхідною (але не достатньою) ознакою можливості появи додаткових мінімумів потенціалу $V_{\text {eff }}$ за деяких $\alpha=L^{2}$. Відповідно, виникають незв'язні області стійких колових орбіт.

Зокрема, для $N=5, x_{0}=1, C=1$ маємо область значень кутового моменту $L \in(0.804,0.821)$, коли виникають два мінімуми потенціалів. При неперервній зміні кутового моменту в області $0 \leq L<0.821$ мають місце мінімуми $V_{\text {eff }}$, що відповідають коловим орбітам з радіусами $x \in[1.094,1.757)$. При $L>0.804$ маємо зв'язну область колових орбіт з радіусами $x \in(2.393, \infty)$. Приклади $V_{\text {eff }}(x)$ та похідних $D V_{\text {eff }}(x)=d V_{\text {eff }} / d x$ показано на Рис.1. Аналогічні незв'язні області колових орбіт маємо при $N=6, L \in(0.771,0.854)$ та при інших $L$ та $N>4.6$. Як було відзначено, $A(x)$ завжди має мінімум (а значить і $V_{\text {eff }}$ при $L=0$ ), це означає існування траєкторій із "зависанням", коли частинка у полі центру може знаходитися у стані спокою з нульовим кутовим моментом.
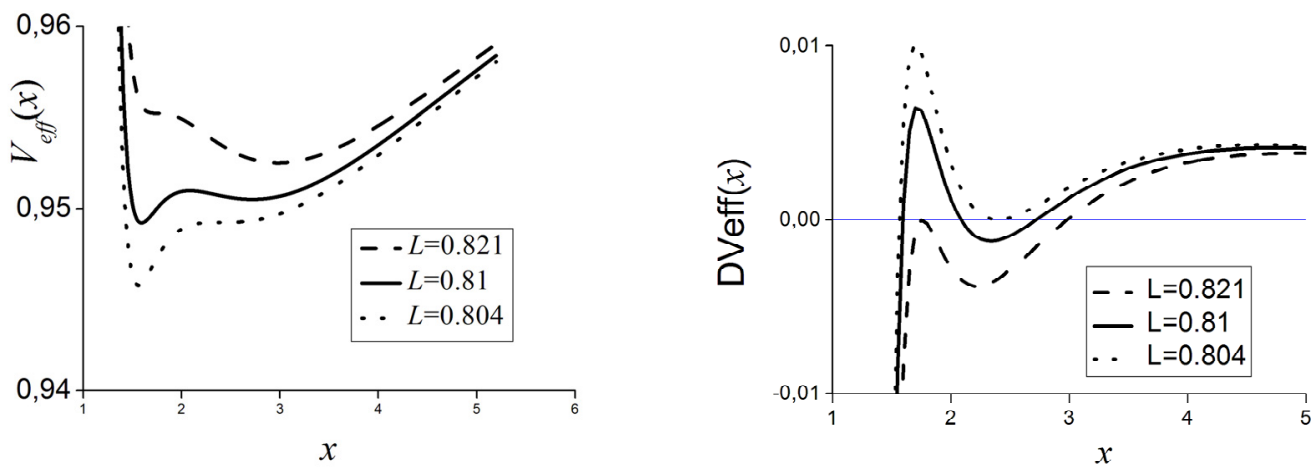

Рис. 1. Графіки потенціалів $V_{\text {eff }}(x)$ (ліворуч) та їх похідних (праворуч) для двох критичних значень $L$ та приклад проміжного значення $L=0.81$, де є два мінімуми ефективного потенціалу $\left(x_{0}=1, C=1, N=5\right)$

4. Обговорення. Результати даної роботи підтверджують, що за наявності скалярного поля можуть виникати області стійких колових орбіт, які не перетинаються. Ця обставина вперше була виявлена для безмасового скалярного поля з мінімальним зв'язком без самодії [6]. У даній роботі аналогічній результат показано для сім'ї часткових розв'язків спільної системи рівнянь Ейнштейна та скалярного поля з ненульовим потенціалом за наявності голої сингулярності у центрі. Зазначимо, що тут присутні випадки зависання частинок з нульовим кутовим моментом. Суттєво відзначити, що потенціал скалярного поля $є$ необмеженим знизу, причому розглядуваний випадок, коли існує гола сингулярність у центрі конфігурації, не суперечить відомим теоремам про "відсутність волосся" в околі чорної діри.

Наявність вищеописаної структури колових орбіт може слугувати для того, щоб експериментально підтвердити або відкинути певні скалярно-польові моделі динамічної темної енергії, які базуються на подібних або аналогічних розв'яз-

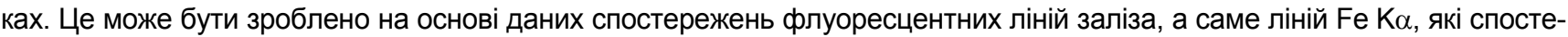
рігають в активних галактичних ядрах [13-15]. Форма цих ліній дає цінну інформацію про характер гравітаційного поля та параметри руху речовини, що їх випромінює. Наявність речовини на різних радіусах, коли розподіл стійких колових орбіт утворює незв'язані області, призведе до деформації ліній Fe Ko, ступінь якої залежатиме від концентрації речо- 
вини у цих областях; причому фрорма ліній може бути схожою на випадок, коли, наприклад, випромінюють два незалежні акреційні диски біля різних об'єктів. Подібна форма ліній дійсно спостерігалася у деяких рентгенівських спектрах активних ядер $[16,17]$. Втім, автори далекі від того, щоб вважати пояснення за участю скалярного поля найбільш прийнятним, оскільки є менш екзотичні і більш реалістичні моделі фрормування ліній [17]. Тим не менш, ретельний розгляд гравітуючих конфігурацій зі скалярним полем у зазначеному вище контексті також заслуговує на увагу.

Публікація містить результати досліджень, проведених при частковій підтримці Державного фонду фрундаментальних досліджень за проектом Ф64/45-2016.

\section{Список використаних джерел}

1. Novosyadlyi B., Pelykh V., Shtanov Yu., Zhuk A. Dark energy and dark matter of the universe: in three volumes / Ed. V. Shulga. - Vol. 1: Dark matter: Observational evidence and theoretical models /. - K.: Akademperiodyka, $-2013 .-380 \mathrm{p}$

2. Яиків Я. С., Александров О. М., Вавилова І. Б. [та ін.] Загальна теорія відносності: горизонти випробувань. - К.: ВАІTЕ, - 2013. - 264 С.

3. Александров А. Н., Вавилова И. Б., Жданов В. И. [и др.] Общая теория относительности: признание временем. - К.: Наукова Думка, 2015. - 330 с.

4. Фишер И. З. Поле скалярного мезона с учетом гравитационных эффектов // ЖЭТФ. - 1948. -Т. 18. - С. 636-640.

5. Janis A. I., Newman E. T., Winicour J. Reality of the Schwarzschild singularity // Phys. Rev. Lett. - 1968. - V. 20. - P. 878-880.

6. Chowdhury A. N., Patil M., Malafarina D., Joshi P. S. Circular geodesics and accretion disks in the Janis-Newman-Winicour and gamma metric spacetimes // Phys. Rev. D. - 2012. - V. 85, id. 104031

7. Бронников К.А., Рубин С.Г Лекции по гравитации и космологии. -М.: МИФИ, 2008. - 460 с.

8. Shikin G. N., Bronnikov K. A. Spherically Symmetric Scalar Vacuum: No-Go Theorems, Black Holes and Solitons // Gravitation and Cosmology. - 2002. -V. 8. - P. 107-116.

9. Nikonov V.V., Tchemarina Ju.V., Tsirulev A.N. A two-parameter family of exact asymptotically flat solutions to the Einstein-scalar field equations // Class. Quant. Grav. - 2008. - V. 25, id.138001.

10. Solovyev D., Tsirulev A., General properties and exact models of static self-gravitating scalar field configurations // Class. Quant. Grav. - 2012. - V.29, id. 055013 .

11. Felder G., Frolov A., Kofman L., Linde A. Cosmology with negative potentials // Phys. Rev. D. - 2002. - V.66, id. 023507.

12. Azreg-Aïnou M. Selection criteria for two-parameter solutions to scalar-tensor gravity GRG. -2010 . - V.42, Is.6. - P. 1427-1456 General Relativity and Gravitation, Volume 42, Issue 6, pp. 1427-1456.

13. Guilbert P.W., Rees M.J. "Cold" material in non-thermal sources // Mon. Notic. Roy. Astron. Soc. - 1988. - Vol. 233. - P. 475-484.

14. Lightman A. P.. White T. R. Effects of cold matter in active galactic nuclei - A broad hump in the X-ray spectra // Astrophys. J. - 1988. - Vol. 335. - P. 57-66.

15. Fabian A. C., Rees M. J., Stella L., et al. X-ray fluorescence from the inner disc in Cygnus X-1// Mon. Notic. Roy. Astron. Soc. - 1989. - V. 238 - P. 729-736.

16. Vasylenko A. A., Fedorova E. V.; Hnatyk B. I., Zhdanov V. I. Evidence for a binary black hole in active nucleus of NGC 1194 galaxy? // Kinemat. Phys. Celest. Bodies. - 2015. - Vol. 31, Is. 1. - P. 13-18.

17. Fedorova , E.; Vasylenko, A.; Hnatyk, B. I.; Zhdanov, V. I. The peculiar megamaser AGN NGC 1194: Comparison with the warped disk candidates NGC 1068 and NGC 4258 // Astronom. Nachr. - 2016. - V. 337, Is. 1-2, p. 96-100.

V. Zhdanov, Dr. Sci., Prof.

Astronomical Observatory of National

Taras Shevchenko University of Kyiv,

O. Stashko, student, Physical Dept.

National Taras Shevchenko University of Kyiv

\section{TEST BODY MOTION IN GRAVITATIONAL FIELD OF A SPHERICALLY SYMMETRICAL CONFIGURATION WITH SCALAR FIELD IN GENERAL RELATIVITY}

We study exact special solutions of the joint system of Einstein equations and scalar field equations with a non-zero self-interaction potential, which describe spherically symmetric static configurations. The space-time is asymptotically flat with a naked singularity at the center. The test body motion is analyzed; we found conditions for existence of non-connected regions of stable circular orbits. We show the existence of static trajectories of particles that hang above the configuration.

В. И. Жданов, д-р физ.-мат. наук, профр.

Астрономическая обсерватория

Киевского национального университета имени Тараса Шевченко,

А. С. Сташко, студент физического факультета

Киевский национальный университет имени Тараса Шевченко

\section{ДВИЖЕНИЕ ПРОБНЫХ ТЕЛ В СТАТИЧЕСКОМ ГРАВИТАЦИОННОМ ПОЛЕ СФЕРИЧЕСКИ-СИММЕТРИЧНОЙ СКАЛЯРНО-ПОЛЕВОЙ КОНФИГУРАЦИИ В ОБЩЕЙ ТЕОРИИ ОТНОСИТЕЛЬНОСТИ}

Изучены частные точные решения совместной системы уравнений Эйнштейна и уравнений скалярного поля с ненулевым потенциалом самодействия, описывающие сферически-симетричные статические конфигурации в случае асимптотически-плоского пространставремени с голой сингулярностью в центре. Для этих решений проанализировано движение пробных тел, которые взаимодействуют только гравитационно. Найдены условия, когда существуют несвязные области устойчивых кругових орбит пробных тел. Показано существование траекторий с нулевым угловым моментом, когда частицы "зависают" на определенном расстоянии от центра.

удк 524.8

С. Парновський, д-р. физ.-мат. наук Астрономічна обсерваторія Київського національного університету імені Тараса Шевченка

\section{ВПЛИВ БЛИЗЬКИХ АТРАКТОРІВ НА ВЕЛИКОМАСШТАБНІ ПЕКУЛЯРНІ РУХИ ГАЛАКТИК}

Розраховано впливи окремих атракторів на мультипольну модель колективних рухів галактик. Виведено формули, що теоретично дозволяють отримувати маси та положення атракторів разом з параметрами мультипольної моделі. Але на сучасному рівні точності оцінки пекулярних швидкостей галактик це ще неможливо.

Вступ. В космології ми вважаємо, що Всесвіт є однорідним та ізотропним. Але на масштабах менших за 200$300 \mathrm{~h}^{-1}$ Мпк він достатньо неоднорідний. $Є$ місця зі збільшеною густиною матерії, наприклад надскупчення галактик, $€$ пустоти або войди, де густина матерії значно менша за середню фонову густину $\rho_{b}$. Різниця густини $\delta$ характеризує відхилення густини у певному місці $\rho(\vec{r})$ від середньої та дорівнює 